\title{
The effect of obesity on patients with mild chronic obstructive pulmonary disease: results from KNHANES 2010 to 2012
}

This article was published in the following Dove Press journal:

International Journal of COPD

24 February 2017

Number of times this article has been viewed

\author{
Ju-Hee Park \\ Jung-Kyu Lee \\ Eun Young Heo \\ Deog Kyeom Kim \\ Hee Soon Chung \\ Division of Pulmonary and Critical \\ Care Medicine, Seoul Metropolitan \\ Government-Seoul National \\ University Boramae Medical Center, \\ Seoul, Republic of Korea
}

Correspondence: Hee Soon Chung Department of Internal Medicine, Seoul Metropolitan Government-Seoul National University Boramae Medical Center, 20 Boramae-ro-5-gil, Dongjak-gu, Seoul 0706I, Republic of Korea

Tel +8228702211

Fax $+82283107 \mid 4$

Email heechung@snu.ac.kr
Purpose: A low body mass index has been associated with high mortalities in patients with chronic obstructive pulmonary disease (COPD), and studies reveal that obesity aggravates the clinical effects of COPD. We investigated the impact of obesity on patients newly identified with COPD.

Patients and methods: This population-based, cross-sectional study, used data from the Korea National Health and Nutrition Examination Survey (KNHANES) conducted from 2010 to 2012. Through analyses of data from this survey, we compared concurrent comorbid diseases, symptoms, and lung functions between an obese and nonobese group of patients with COPD. Results: In total, 618 participants were diagnosed with COPD and the average forced expired volume in $1 \mathrm{~s}\left(\mathrm{FEV}_{1}\right)$ was $79.47 \% \pm 0.69 \%$. Of the total, $30.5 \%$ of the subjects were categorized into an obese group. Subjects in the obese group were likely to have metabolic syndrome $(P<0.001)$, hypertension $(P=0.02)$, and a higher number of comorbidities compared to the nonobese group $(2.3 \pm 0.1$ vs $2.0 \pm 0.1, P=0.02)$. In addition, subjects in the obese group showed a lower forced vital capacity (FVC) than subjects in the nonobese group, even after adjusting for covariates (average $\mathrm{FVC} \%, 89.32 \pm 1.26$ vs $92.52 \% \pm 0.72 \%, P=0.037$ ). There were no significant differences in the adjusted $\mathrm{FEV}_{1} \%$ and adjusted $\mathrm{FEV}_{1} / \mathrm{FVC}$ between the groups.

Conclusions: Among subjects newly identified with mild COPD, participants in the obese group had more comorbid conditions and showed a lower FVC compared with subjects in the nonobese group, even after adjustment of covariates. These findings show that a combination of obesity and COPD may be a severe phenotype; therefore, early attention should be paid to obesity for the management of COPD patients.

Keywords: COPD, obesity, comorbidity, KNHANES, spirometry, lung function

\section{Introduction}

Chronic obstructive pulmonary disease (COPD) is defined as a fixed airflow limitation and is associated with a systemic inflammatory response caused by smoking. ${ }^{1}$ Patients with COPD have numerous comorbid conditions, such as cardiovascular disease or lung cancer, which share smoking as a risk factor. Other comorbid conditions, including anxiety, depression, osteoporosis, anemia, diabetes mellitus, metabolic syndrome, and obesity, are commonly concurrent with the presence of COPD. ${ }^{2,3}$ These comorbid conditions influence the health status and outcome of patients with COPD. ${ }^{4}$

Obesity, an increasing global health problem, ${ }^{5}$ is known as an important comorbidity. Numerous pulmonary complications are observed in obese patients. ${ }^{6,7}$ Although it was performed on different ethnic background, the prevalence of obesity in patients with COPD has been reported to be in a range from $10 \%$ to $50 \%,{ }^{8,9}$ and 
studies have investigated the relationship between obesity and COPD. However, it is somewhat unclear if obesity actually has a detrimental impact on patients with COPD. For example, a low body mass index (BMI) has been regarded as an independent risk factor of mortality in patients with COPD. ${ }^{10}$ However, several conflicting studies reported more respiratory symptoms, worse restriction of daily activities, worse health-related quality of life, or more health care use in obese patients with COPD. ${ }^{9,11,12}$ The impact of obesity on COPD is an ongoing controversy to discuss. ${ }^{13}$ In addition, pharmacological and nonpharmacological treatment for COPD may obscure the effect of comorbidities, including obesity. Furthermore, no study has investigated whether obesity affects the health status of patients with mild COPD and no previous history of treatment.

This study analyzed the findings from a general populationbased database to identify whether clinical characteristics, including symptoms, quality of life, comorbid diseases, and lung function, were associated with the presence of obesity in patients with COPD and no history of treatment.

\section{Materials and methods Study population}

The Korean National Health and Nutrition Examination Survey (KNHANES) is a population-based health and nutritional survey issued by the Korea Center for Disease Control and Prevention. ${ }^{14}$ KNHANES V (the 5 th version of KNHANES, which was conducted during 2010-2012) was conducted during 2010-2012 and is composed of the following four parts: a health interview survey, a nutrition survey, a health behavior survey, and a health examination survey conducted by trained interviewers. Participants were selected using a stratified, multistage, clustered probability sampling design. Sampling units were based on household registries, including geographic area, age, and sex. The sample represents the total population of Korea. ${ }^{15}$ This present study applied the KNHANES database, in which all information was anonymized, and was given an exemption from ethical review in Seoul Metropolitan Government-Seoul National University Boramae Medical Center because we used public data provided by KNHANES (IRB No 07-2016-26/111).

COPD was defined as a ratio of the forced expiratory volume in $1 \mathrm{~s}\left(\mathrm{FEV}_{1}\right) /$ forced vital capacity $(\mathrm{FVC})<0.7,{ }^{4}$ among former or current smokers with at least 10 pack-years. We excluded participants who were already diagnosed with COPD and those who were under treatment for COPD. As spirometry is performed only in subjects aged $>40$ years, the cohort consisted of patients aged $>40$ years.

\section{Measurement and classification of variables}

Obesity was defined according to the criteria recommended by the Korean Society for the Study of Obesity, which define a BMI $\geq 25.0 \mathrm{~kg} / \mathrm{m}^{2}$ as obese. ${ }^{16}$ BMI was calculated as weight in kilograms divided by height in meters squared. Waist circumference was measured midway between the costal margin and the iliac crest in a sitting position at the end of a normal expiration. Self-reported questionnaires were used to determine smoking status (former/current) and smoking pack-years.

Blood samples were obtained after overnight fasting, and the levels of total cholesterol, low-density lipoprotein cholesterol, high-density lipoprotein cholesterol, triglycerides, and fasting glucose were measured. Metabolic syndrome was defined according to the criteria established by the International Diabetes Federation, ${ }^{17}$ and central obesity was defined using a Korean standard. ${ }^{18}$ Accordingly, subjects with central obesity (waist circumference $\geq 90 \mathrm{~cm}$ for men and $\geq 85 \mathrm{~cm}$ for women) and 2 of 4 factors of metabolic syndrome were included in the study. The factors were serum triglyceride levels $\geq 150 \mathrm{mg} / \mathrm{dL}$, high-density lipoprotein cholesterol levels $<40 \mathrm{mg} / \mathrm{dL}$ for men and $<50 \mathrm{mg} / \mathrm{dL}$ for women, systolic blood pressure $\geq 130 \mathrm{mmHg}$ or diastolic blood pressure $\geq 85 \mathrm{mmHg}$, and fasting plasma glucose $\geq 100 \mathrm{mg} / \mathrm{dL}$.

Hypertension was defined by a mean systolic blood pressure $\geq 140 \mathrm{mmHg}$ or diastolic blood pressure $\geq 90 \mathrm{mmHg}$ and/ or current usage of antihypertensive medications. ${ }^{19}$ Diabetes mellitus was defined by a fasting glucose $>126 \mathrm{mg} / \mathrm{dL}$ or hemoglobin A1c $>6.5 \%$ or current usage of medication for glycemic control. ${ }^{20}$

Osteoporosis was defined as lumbar spine (L1-4), total femur, or femur neck T-score of $<2.5$ using dual-energy $\mathrm{X}$-ray absorptiometry, ${ }^{21}$ or current usage of osteoporosis medications. Other comorbidities, including dyslipidemia, coronary artery disease, stroke, chronic renal failure, osteoarthritis, rheumatoid arthritis, atopic dermatitis, lung cancer, pulmonary tuberculosis, and depression, were obtained from self-reported questionnaires. The total number of comorbid conditions was counted and compared between the two groups.

The presence of a wheezing episode was recorded as one of the disease symptoms. The validated Korean version of the EuroQol five dimensions questionnaire (EQ-5D ${ }^{\mathrm{TM}}$ ) was used for an evaluation of quality of life. The EQ-5D is a generic questionnaire used to assess the health-related quality of life in patients with chronic disease. ${ }^{22}$ The descriptive system comprises the following five dimensions: mobility, self-care, 
usual activities, pain/discomfort, and anxiety/depression. The average score of the EQ-5D index was calculated by using the South Korean-specific tariff that is based on the time-trade-off method. ${ }^{23}$

Spirometry was performed for subjects aged $>40$ years and using standardized equipment by trained technician according to the guidelines from the American Thoracic Society/European Respiratory Society. ${ }^{24}$ Prebronchodilator spirometry results were measured and analyzed based on a reference value from a predictive equation of the Korean population. ${ }^{25}$

\section{Statistical analysis}

KNHANES data provided population weights. The sample weights of the participants were constructed to represent the Korean population by accounting for the complex survey design, survey nonresponse, and poststratification. ${ }^{14}$ We applied the complex sample design of the survey using stratification, sampling weight variables, and clustering variables for prevalence production. Categorical variables were reported as weighted percentages, and continuous variables were reported as mean \pm standard error (SE). To compare the characteristics of each group, general linear regression (stata command, svyset: regress) was used for continuous variables and a chi-squared test (stata command, svyset: tab) was used for categorical variables.

To compare lung function with the presence of obesity, the adjusted mean values of $\mathrm{FEV}_{1} \%, \mathrm{FVC} \%$, and $\mathrm{FEV}_{1} / \mathrm{FVC}$ were compared between groups (stata command, svypxcat). Adjustment variables were age, sex, and height, which may independently affect lung function, smoking status, history of tuberculosis, and the presence of metabolic syndrome, and that were significantly different between the two groups. A $P$-value of $<0.05$ was considered statistically significant. All analyses were performed using STATA version 14.2 (StataCorp, College Station, TX, USA).

\section{Results}

Of the 22,697 participants in the 2010-2012 survey, we included 9,488 participants who had completed a spirometry evaluation. Among the 9,488 subjects who underwent a lung function test, 1,073 had an airflow limitation $\left(\mathrm{FEV}_{1} / \mathrm{FVC}<0.7\right)$. After exclusion of 445 subjects (never a smoker, smoker $<10$ pack-years, or uncertain smoking history), 628 subjects were defined as having COPD. After exclusion of 10 subjects who were previously diagnosed with or treated for COPD, the data of 618 subjects newly identified with COPD were analyzed for the study

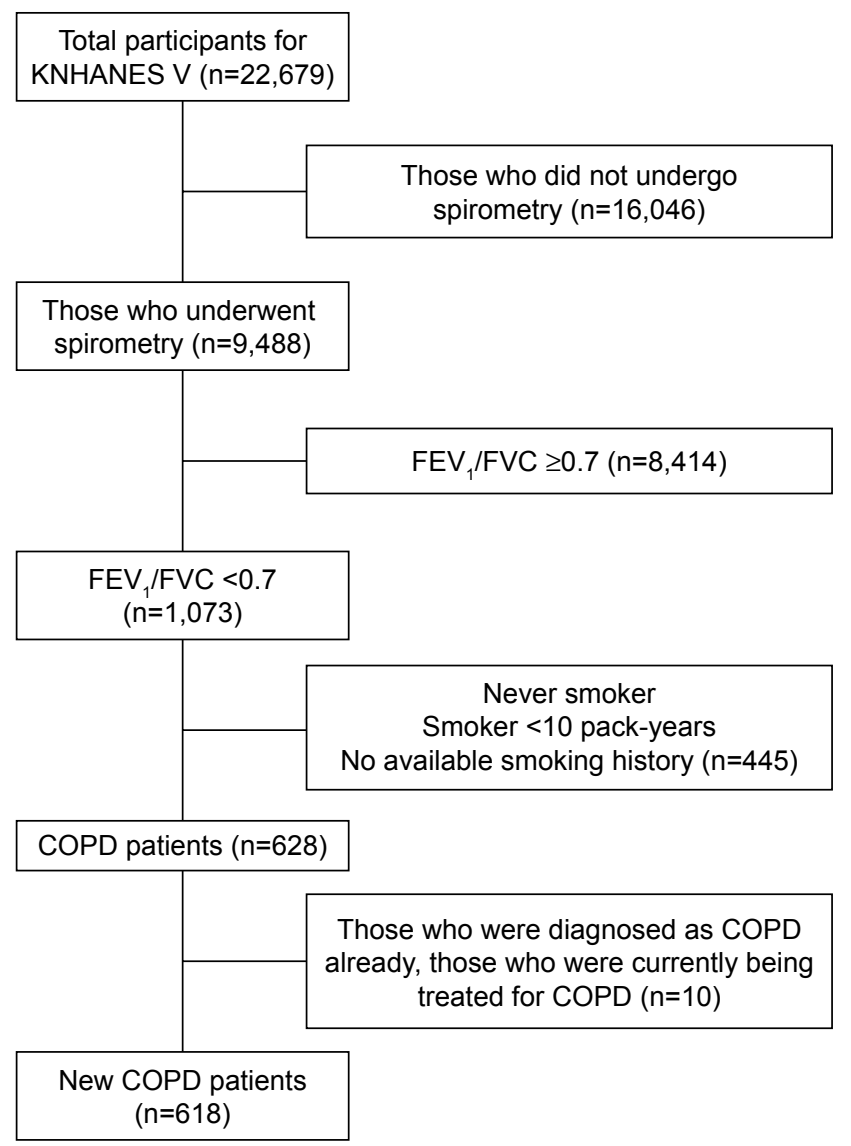

Figure I Flowchart for participants through the study.

Abbreviations: COPD, chronic obstructive pulmonary disease; $F E V_{1}$, forced expiratory volume in I s; FVC, forced vital capacity; KNHANES V, the 5th version of Korea National Health and Nutrition Examination Survey which was conducted during 2010-2012.

(Figure 1). The included subjects were $63.56 \pm 0.54$ years old (range 40-91) on average and consisted of 605 (97\%) men. The mean BMI value was $23.57 \pm 0.14 \mathrm{~kg} / \mathrm{m}^{2}$. The average smoking history was $35.10 \pm 0.94$ pack-years. The mean $\mathrm{FEV}_{1}(\%$, pred) was $79.47 \% \pm 0.69 \%$, mean $\mathrm{FVC}(\%$, pred $)$ was $91.83 \% \pm 0.64 \%$, and mean $\mathrm{FEV}_{1} / \mathrm{FVC}$ was $0.63 \pm 0.00$. The majority of the enrolled subjects with COPD were categorized as "mild" COPD cases in terms of severity assessed by $\mathrm{FEV}_{1}(\%$, pred), which was nearly an average of $80 \%$. Among 618 total subjects, stage 1, 2, and 3 had 308 (51\%), $298(47 \%)$, and $13(2 \%)$, respectively. There was no subject belonging to stage 4 . In 424 nonobese subjects, $225(53 \%), 190(44 \%)$, and 9 (2\%) were classified as stage 1,2 , and 3 according to the Global Initiative for Chronic Obstructive Lung Disease (GOLD) stage. In 194 obese subjects, 82 (44\%), 108 (54\%), and 4 (2\%) belonged to stage 1,2, and 3, respectively. Chi-squared test (stata command, svyset: tab) was used for comparison of categorical variables, but no significant difference was found between nonobese and obese group $(P=0.150)$. 
Obese subjects (BMI $>25 \mathrm{~kg} / \mathrm{m}^{2}$ ) comprised $30.5 \%$ of the subjects, and multiple variables were compared between the obese and nonobese groups (Table 1).

Subjects in the obese group were younger than the other group $(P=0.03)$, but no difference was observed in sex of the subjects between groups. There were more former smokers in the obese group $(P=0.04)$, but smoking pack-years did not differ between the groups. Subjects in the obese group had a higher prevalence of metabolic syndrome $(41.5 \%$ vs $7.1 \%$, $P<0.001)$, including higher triglycerides $(P=0.04)$ and fasting plasma glucose $(P=0.02)$ levels. Hypertension was more common $(P=0.02)$ in the obese group, whereas a history of tuberculosis was less common $(P=0.05)$. The total number of comorbid conditions was higher in the obese group than the nonobese group ( $2.3 \pm 0.1$ vs $2.0 \pm 0.1 ; P=0.02)$.

Wheezing episodes seemed to be more common in the obese group, but there was no statistical significance. The EQ-5D index was comparable between the two groups

Table I Demographic information and comorbidities of obese and nonobese patients with COPD

\begin{tabular}{|c|c|c|c|}
\hline Variable & $\begin{array}{l}\text { Obese, } \\
(n=194)\end{array}$ & $\begin{array}{l}\text { Nonobese, } \\
(n=424)\end{array}$ & $P$-value \\
\hline Age (years) & $61.8 \pm 0.8$ & $64.2 \pm 0.6$ & 0.03 \\
\hline Male & 98.5 & 97.2 & 0.51 \\
\hline Height $(\mathrm{cm})$ & $166.7 \pm 0.6$ & $166.4 \pm 0.3$ & 0.68 \\
\hline Weight (kg) & $74.8 \pm 0.6$ & $61.3 \pm 0.4$ & $<0.00 \mathrm{I}$ \\
\hline BMI $\left(\mathrm{kg} / \mathrm{m}^{2}\right)$ & $26.8 \pm 0.1$ & $22.1 \pm 0.1$ & $<0.001$ \\
\hline Waist circumference $(\mathrm{cm})$ & $93.5 \pm 0.5$ & $82.1 \pm 0.4$ & $<0.001$ \\
\hline \multicolumn{4}{|l|}{ Smoking } \\
\hline Current smoker & 38.7 & 49.9 & 0.04 \\
\hline Former smoker & 61.2 & 50.0 & \\
\hline Smoking pack-years & $36.7 \pm 1.7$ & $34.3 \pm 1.1$ & 0.25 \\
\hline \multicolumn{4}{|l|}{ Laboratory findings } \\
\hline Total cholesterol (mg/dL) & $194.8 \pm 3.9$ & $188.5 \pm 2.3$ & 0.18 \\
\hline Triglycerides (mg/dL) & $184.0 \pm 10.8$ & $159.4 \pm 1 \mid .3$ & 0.04 \\
\hline Fasting plasma glucose (mg/dL) & $107.2 \pm 2.4$ & $101.1 \pm 1.1$ & 0.02 \\
\hline Metabolic syndrome & 45.1 & 7.1 & $<0.00 \mathrm{I}$ \\
\hline \multicolumn{4}{|l|}{ Comorbid conditions } \\
\hline Hypertension & 64.8 & 51.9 & 0.02 \\
\hline Diabetes mellitus & 22.6 & 17.4 & 0.21 \\
\hline Dyslipidemia & 78.4 & 78.1 & 0.93 \\
\hline Coronary artery disease & 5.8 & 2.9 & 0.21 \\
\hline Stroke & 2.6 & 2.1 & 0.69 \\
\hline Chronic renal failure & 0.3 & 0.8 & 0.27 \\
\hline Osteoporosis & 16.7 & 15.2 & 0.71 \\
\hline Osteoarthritis & 14.0 & 10.2 & 0.27 \\
\hline Rheumatoid arthritis & 0.6 & 1.3 & 0.44 \\
\hline Atopic dermatitis & 2.3 & 3.9 & 0.44 \\
\hline History of lung cancer & 0.2 & 0.1 & 0.96 \\
\hline History of pulmonary tuberculosis & 7.8 & 15.6 & 0.05 \\
\hline Depression & 10.4 & 8.1 & 0.45 \\
\hline Number of comorbidities & $2.3 \pm 0.1$ & $2.0 \pm 0.1$ & 0.02 \\
\hline
\end{tabular}

Note: Data presented as mean \pm SE or percentage.

Abbreviations: BMI, body mass index; COPD, chronic obstructive pulmonary disease; $\mathrm{SE}$, standard error.
Table 2 Symptoms and unadjusted pulmonary function of obese and nonobese patients with COPD

\begin{tabular}{llll}
\hline Variable & $\begin{array}{l}\text { Obese, } \\
(\mathbf{n}=1 \mathbf{1 9 4})\end{array}$ & $\begin{array}{l}\text { Nonobese, } \\
(\mathbf{n}=\mathbf{4 2 4})\end{array}$ & P-value \\
\hline \multicolumn{2}{l}{ Symptom and quality of life } & & \\
Wheezing & 12.6 & 7.6 & 0.14 \\
EQ-5D index & $0.92 \pm 0.01$ & $0.93 \pm 0.00$ & 0.45 \\
Spirometry & & & \\
FEV, L & $2.55 \pm 0.05$ & $2.50 \pm 0.03$ & 0.44 \\
FEV $_{1}, \%$ pred & $78.70 \pm 1.12$ & $79.81 \pm 0.86$ & 0.43 \\
FVC, L & $3.98 \pm 0.08$ & $3.96 \pm 0.04$ & 0.82 \\
FVC, \% pred & $88.98 \pm 1.20$ & $93.08 \pm 0.75$ & 0.01 \\
FEV $/$ FVC & $0.64 \pm 0.00$ & $0.62 \pm 0.00$ & 0.04 \\
\hline
\end{tabular}

Note: Data presented as mean \pm SE or percentage.

Abbreviations: COPD, chronic obstructive pulmonary disease; EQ-5D ${ }^{\mathrm{TM}}$, EuroQol five dimensions questionnaire; FEV, forced expiratory volume in I s; FVC, forced vital capacity; \% pred, \% of predicted value; QOL, quality of life; SE, standard error.

(Table 2). FVC (\%, pred, $P=0.01)$ and $\mathrm{FEV}_{1} / \mathrm{FVC}(P=0.04)$ were significantly lower in the obese group.

After adjusting for age, sex, height, smoking status, history of tuberculosis, and metabolic syndrome, subjects in the obese group showed a significantly lower FVC compared with subjects of the nonobese group $(89.32 \% \pm 1.26 \%$ vs $92.52 \% \pm 0.72 \%, P=0.037)$. There was no significant difference in $\mathrm{FEV}_{1}(79.54 \% \pm 1.32 \%$ vs $79.92 \% \pm 0.85 \%, P=0.829)$ and $\mathrm{FEV}_{1} / \mathrm{FVC}(0.63 \pm 0.00$ vs $0.62 \pm 0.00, P=0.543)$ between the groups (Figure 2).

\section{Discussion}

This study found that obesity is associated with more comorbid conditions and lower FVC in subjects newly identified with mild COPD.

It is well known that obesity may be accompanied by numerous pathological conditions. Similar to the findings in several previous studies, this study found that obese patients have more comorbid conditions than nonobese patients. ${ }^{26,27}$ In this study, obese patients with COPD presented with a higher prevalence of comorbid conditions, hypertension, and metabolic syndrome than nonobese patients with COPD. Hypertension and metabolic syndrome are common risk factors of cardiovascular disease. ${ }^{28}$ Cardiovascular disease is a well-known risk factor of increased hospital admission and mortality rate in patients with $\mathrm{COPD},{ }^{29}$ which explains $9 \%-27 \%$ of their deaths in large clinical trials. ${ }^{30-32}$ Therefore, obesity should be considered as a deteriorating prognostic factor when combined to COPD.

Obese patients with COPD presented with lower FVC than non-obese COPD patients during a pulmonary function test. This is similar to the results of numerous studies, ${ }^{33-35}$ with the 

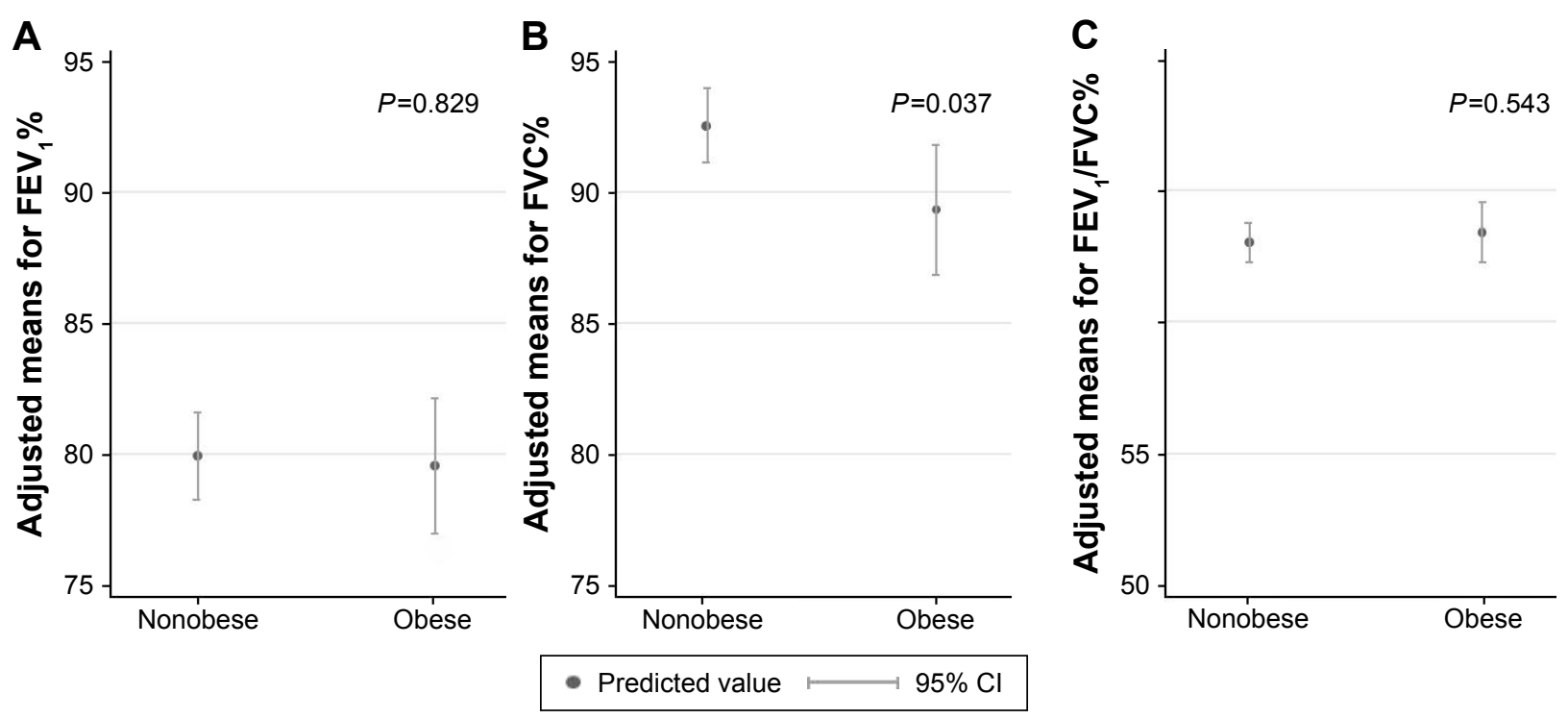

Figure 2 Adjusted lung function of obese and nonobese patients with COPD.

Notes: Adjusted by age, sex, height, smoking status, history of tuberculosis, and metabolic syndrome. (A) FEV,\%; (B) FVC\%; (C) FEV/FVC.

Abbreviations: COPD, chronic obstructive pulmonary disease; $\mathrm{Cl}$, confidential interval; $\mathrm{FVC}$, forced vital capacity; $\mathrm{FEV}_{1}$, forced expiratory volume in I s.

exception of a few reports. ${ }^{36}$ It has been thought that a lower FVC in obese patients is attributed to mechanical restriction of ventilation function. ${ }^{35}$ Obesity impairs the diaphragm's ability to descend and decreases the compliance of the thoracic cage, which leads to a decrease in functional residual capacity and total lung capacity, eventually resulting in restrictive extrathoracic ventilation patterns. ${ }^{12}$ In addition, a lower FVC may indicate hyperinflation of the lung due to airflow obstruction. Increases in hyperinflation by airflow obstruction may result in a reduction in FVC due to an increase in residual volume (total lung capacity $=$ residual volume + vital capacity). An American Thoracic Society/European Respiratory Society consensus paper stated that a low FVC with or without a low $\mathrm{FEV}_{1} / \mathrm{FVC}$ may be due to an obstructive ventilatory abnormality. ${ }^{37}$ In a previous study, vital capacity and inspiratory capacity decreased linearly with the progression of airflow obstruction throughout a continuum of hyperinflation from mild to more severe COPD ${ }^{38}$ In this study, patients with COPD seemed to show more wheezing episode $(12.6 \%$ vs $7.65 \%)$, but without statistical significance $(P=0.140)$.

These results suggest that management of obesity may be necessary for patients with even mild COPD. The current guideline, the GOLD, included cessation of smoking as a nonpharmacologic treatment, as well as physical activity, rehabilitation, and vaccination. ${ }^{39}$ In our study, patients with COPD and without obesity presented with a lower number of comorbidities and better FVC. Therefore, weight reduction may be included as another therapeutic recommendation for patients with mild COPD and with an obese phenotype..$^{39}$
This study has several strengths. First, it analyzed a treatment-naïve general population. COPD treatments may act as possible confounders. For example, COPD medications improve lung function test results, ${ }^{30,40}$ and systemic corticosteroid usage for acute exacerbation may increase oral intake or risk of truncal obesity, especially in advanced diseases. ${ }^{41}$ Second, this was a nationwide, cross-sectional study based on reliable data with an appropriate survey design. Third, we analyzed blood pressure, fasting plasma glucose levels, and hemoglobin A1c levels for evaluation of comorbid conditions, including hypertension and diabetes. This provided more detailed analyses than a mere examination of the presence of those conditions.

This study also has several limitations. First, as a cross-sectional study, we were unable to verify the causality between obesity and differences in clinical outcomes of COPD. Second, as postbronchodilator spirometry was not available for this survey, we used prebronchodilator spirometry and fixed $\mathrm{FEV}_{1} / \mathrm{FVC}$ ratio criteria for COPD diagnosis. It might have overestimated the number of COPD subjects and resulted in unwanted inclusion of asthmatic subjects in the study. To avoid this, we supplemented smoking history to define COPD and tried to exclude participants with smoking history $<10$ pack-years and past treatment history. Third, there were insufficient data for evaluating symptoms or quality of life relevant to COPD. For objective indicators, oxygen saturation value or exercise capacity was not available. For symptoms and quality of life, an appropriate questionnaire or the scoring system (eg, St George's 
Respiratory Questionnaire, modified Medical Research Council, and COPD assessment test) was not available. Fourth, in this study, obesity did not influence the patient's quality of life. This was in disagreement with a couple of previous studies with similar design that found a decreased quality of life in obese patients with COPD. ${ }^{42,43}$ This may have been due to the inclusion of only new COPD cases, which may have been characterized by milder disease.

\section{Conclusion}

Among patients newly identified with COPD by a nationwide survey, obese participants have more comorbid conditions and showed a lower FVC than nonobese group even after adjustment of covariates. This suggests that the combination of obesity and COPD could present a severe phenotype, therefore attention needs to be paid to the management of obesity, even in mild COPD patients.

\section{Author contributions}

JHP designed the study, analyzed data, and wrote the manuscript. HSC planned the study and provided critical revision of the manuscript for important intellectual content and final approval of the manuscript. JKL, EYH, and DKK designed the study, analyzed data, and provided critical revision of the manuscript for important intellectual content. All authors contributed toward data analysis, drafting and revising the paper, and agree to be accountable for all aspects of the work.

\section{Disclosure}

The authors report no conflicts of interest in this work.

\section{References}

1. Fabbri L, Luppi F, Beghe B, Rabe K. Complex chronic comorbidities of COPD. Eur Respir J. 2008;31(1):204.

2. Van Manen J, Bindels P, IJzermans C, Van der Zee J, Bottema B, Schade E. Prevalence of comorbidity in patients with a chronic airway obstruction and controls over the age of 40. J Clin Epidemiol. 2001;54(3):287-293.

3. Cavaillès A, Brinchault-Rabin G, Dixmier A, et al. Comorbidities of COPD. Eur Respir Rev. 2013;22(130):454-475.

4. Global Initiative for Chronic Obstructive Lung Disease (GOLD).Global strategy for the diagnosis, management, and prevention of COPD. Available from: http://www.goldcopd.com. Accessed October 20, 2016.

5. World Health Organization. Obesity: Preventing and Managing the Global Epidemic. World Health Organization; 2000. Available from: http://www. who.int/iris/handle/10665/42330. Accessed October 20, 2016.

6. Bhasin D, Sharma A, Sharma SK. Pulmonary complications of obesity. Obesity (Silver Spring). 2015:131-144.

7. Jubber A. Respiratory complications of obesity. Int $J$ Clin Pract. 2004;58(6):573-580.

8. Steuten LM, Creutzberg EC, Vrijhoef HJ, Wouters EF. COPD as a multicomponent disease: inventory of dyspnoea, underweight, obesity and fat free mass depletion in primary care. Prim Care Respir J. 2006;15(2):84-91.

9. Eisner MD, Blanc PD, Sidney S, et al. Body composition and functional limitation in COPD. Respir Res. 2007;8(1):1.
10. Landbo C, Prescott E, Lange P, Vestbo J, Almdal TP. Prognostic value of nutritional status in chronic obstructive pulmonary disease. Am J Respir Crit Care Med. 1999;160(6):1856-1861.

11. Divo MJ, Cabrera C, Casanova C, et al. Comorbidity distribution, clinical expression and survival in COPD patients with different body mass index. Chronic Obstr Pulm Dis. 2014;1(2):229-238.

12. O'Donnell DE, Ciavaglia CE, Neder JA. When obesity and chronic obstructive pulmonary disease collide. Physiological and clinical consequences. Ann Am Thorac Soc. 2014;11(4):635-644.

13. Franssen F, O'Donnell D, Goossens G, Blaak E, Schols A. Obesity and the lung: 5 Obesity and COPD. Thorax. 2008;63(12):1110-1117.

14. Kweon S, Kim Y, Jang M-J, et al. Data resource profile: The Korea National Health and Nutrition Examination Survey (KNHANES). Int J Epidemiol. 2014;43(1):69-77.

15. Korea Center for Disease Control and Prevention (KCDC). The Fifth Korea National Health and Nutrition Examination Survey (NHANES V) 2010-2012. Seoul, South Korea: Ministry of Health and Welfare \& Korea Centers for Disease Control and Prevention; 2010.

16. Korean Endocrine Society and Korean Society for the Study of Obesity. Management of obesity, 2010 recommendation. Endocrinol Metab. 2010; 25(4):301-304.

17. Alberti G, Zimmet P, Shaw J. Metabolic syndrome - a new worldwide definition. A consensus statement from the International Diabetes Federation. Diabet Med. 2006;23(5):469-480.

18. Park HS, Lee SY, Kim SM, Han JH, Kim DJ. Prevalence of the metabolic syndrome among Korean adults according to the criteria of the International Diabetes Federation. Diabetes Care. 2006;29(4):933-934.

19. Mancia G, Fagard R, Narkiewicz K, et al. 2013 ESH/ESC guidelines for the management of arterial hypertension: the Task Force for the Management of Arterial Hypertension of the European Society of Hypertension (ESH) and of the European Society of Cardiology (ESC). Blood Press. 2013;22(4):193-278.

20. American Diabetes Association. Standards of medical care in diabetes2013. Diabetes Care. 2013;(36 Suppl 1):S11-S66.

21. World Health Organization. Assessment of Fracture Risk and its Application to Screening for Postmenopausal Osteoporosis: Report of a WHO Study Group. Rome, Italy: World Health Organization; 1992. Available from: http://www.who.int/iris/handle/10665/39142. Accessed October 20, 2016.

22. Group TE. EuroQol-a new facility for the measurement of health-related quality of life. Health Policy. 1990;16(3):199-208.

23. Lee YK, Nam HS, Chuang LH, et al. South Korean time trade-off values for EQ-5D health states: modeling with observed values for 101 health states. Value Health. 2009;12(8):1187-1193.

24. Miller MR, Hankinson J, Brusasco V, et al. Standardisation of spirometry. Eur Respir J. 2005;26(2):319-338.

25. Choi JK, Paek D, Lee JO. Normal predictive values of spirometry in Korean population. Tuberc Respir Dis (Seoul). 2005;58(3):230-242.

26. Jo YS, Choi SM, Lee J, et al. The relationship between chronic obstructive pulmonary disease and comorbidities: a cross-sectional study using data from KNHANES 2010-2012. Respir Med. 2015;109(1):96-104.

27. Varela MVL, de Oca MM, Halbert R, et al. Comorbidities and health status in individuals with and without COPD in five Latin American cities: the PLATINO study. Arch Bronconeumol. 2013;49(11):468-474.

28. Mottillo S, Filion KB, Genest J, et al. The metabolic syndrome and cardiovascular risk: a systematic review and meta-analysis. $J$ Am Coll Cardiol. 2010;56(14):1113-1132.

29. Briggs A, Spencer M, Wang H, Mannino D, Sin DD. Development and validation of a prognostic index for health outcomes in chronic obstructive pulmonary disease. Arch Intern Med. 2008;168(1):71-79.

30. Calverley PM, Anderson JA, Celli B, et al. Salmeterol and fluticasone propionate and survival in chronic obstructive pulmonary disease. N Engl J Med. 2007;356(8):775-789.

31. McGarvey LP, Magder S, Burkhart D, et al. Cause-specific mortality adjudication in the UPLIFT® COPD trial: findings and recommendations. Respir Med. 2012;106(4):515-521. 
32. Wise RA, Anzueto A, Cotton D, et al. Tiotropium Respimat inhaler and the risk of death in COPD. N Engl J Med. 2013;369(16):1491-1501.

33. Ochs-Balcom HM, Grant BJ, Muti P, et al. Pulmonary function and abdominal adiposity in the general population. J S C Med Assoc. 2006;129(4): 853-862.

34. Sahebjami H, Gartside PS. Pulmonary function in obese subjects with a normal FEV1/FVC ratio. J S C Med Assoc. 1996;110(6):1425-1429.

35. van den Bemt L, van Wayenburg C, Smeele I, Schermer T. Obesity in patients with COPD, an undervalued problem? Thorax. 2009;64(7):640.

36. Al Ghobain M. The effect of obesity on spirometry tests among healthy non-smoking adults. BMC Pulm Med. 2012;12(1):1.

37. Pellegrino R, Viegi G, Brusasco V, et al. Interpretative strategies for lung function tests. Eur Respir J. 2005;26(5):948-968.

38. Deesomchok A, Webb KA, Forkert L, et al. Lung hyperinflation and its reversibility in patients with airway obstruction of varying severity. COPD. 2010;7(6):428-437.
39. Vestbo J, Hurd SS, Agustí AG, et al. Global strategy for the diagnosis, management, and prevention of chronic obstructive pulmonary disease: GOLD executive summary. Am J Respir Crit Care Med. 2013;187(4): $347-365$.

40. Tashkin DP, Celli B, Senn S, et al. A 4-year trial of tiotropium in chronic obstructive pulmonary disease. N Engl J Med. 2008;359(15): $1543-1554$.

41. Dallman MF, la Fleur SE, Pecoraro NC, Gomez F, Houshyar H, Akana SF. Minireview: glucocorticoids - food intake, abdominal obesity, and wealthy nations in 2004. Endocrinology. 2004;145(6):2633-2638.

42. Lambert AA, Putcha N, Drummond MB, et al. Obesity is associated with increased morbidity in moderate to severe COPD. Chest. 2017; 151(1):68-77.

43. Cecere LM, Littman AJ, Slatore CG, et al. Obesity and COPD: associated symptoms, health-related quality of life, and medication use. COPD. 2011;8(4):275-284.
International Journal of COPD

\section{Publish your work in this journal}

The International Journal of COPD is an international, peer-reviewed journal of therapeutics and pharmacology focusing on concise rapid reporting of clinical studies and reviews in COPD. Special focus is given to the pathophysiological processes underlying the disease, intervention programs, patient focused education, and self management protocols.

\section{Dovepress}

This journal is indexed on PubMed Central, MedLine and CAS. The manuscript management system is completely online and includes a very quick and fair peer-review system, which is all easy to use. Visit http://www.dovepress.com/testimonials.php to read real quotes from published authors.

Submit your manuscript here: http://www.dovepress.com/international-journal-of-chronic-obstructive-pulmonary-disease-journal 